\title{
A STUDY TO ASSESS THE EFFECTIVENESS OF ACUPRESSURE IN REDUCING DYSIMENORRHOEA AMONG NURSING STUDENTS OF A SELECTED COLLEGE OF NURSING AT MANGALURU.
}

\section{Nilima Kalai \\ Selinamma Devasia (Sr. Dhanya)*} M.Sc Nursing student

KEY WORDS: Acupressure, dysmenorrhoea, nursing student.

Background Acupressure is an ancient healing art that uses fingers to press key points on the surface of the skin to stimulate body's natural self-curative abilities. When these points are pressed, they release muscular tension and promote the circulation of blood and body's life force to aid healing. It has been reported that dysmenorrhoea can be successfully relieved by acupressure at Qihai (CV6), Guanyuan (CV4), Taichong (LIV3), Xuehai(SP10), Sanyinjiao (SP6). The sanyinjio acupoint is commonly used to induce labour and relieve pain during dysmenorrhoea. Dysmenorrhoea is a common problem among girls and acupressure is an effective non-invasive procedure to relieve pain. Acupoint Sanyinjiao (SP6) was selected for the study because it is the acupoint of choice in gynaecology and easy for girls to locate and apply pressure to without medical assistance. The aim of the study was to assess the effectiveness of acupressure in reducing dysmenorrhoea among nursing students. Materials and Method A quasi experimental time series nonequivalent control group design was used for the present study. Forty nursing students who met the inclusion criteria was selected by using purposive sampling technique. Baseline proforma and numeric pain scale was used to assess the level of pain. Data analysis was done by using descriptive and inferential statistics such as frequency, range, mean, median, standard deviation, uppaired "t" test and ANOVA for repeated measures. Result There was significant difference in pain between the two group soon after, after 30 minutes and after 1 hour. The mean score of dysmenorrhoea among students before acupressure (7.95) was higher than immediately after the intervention (6.35). After 30 minutes the mean score was 4.25 and after 1 hour the mean score was (1.25). The computed value of ANOVA $(F=344.881)$ was found to be significant $(p<0.05)$ in reducing dysmenorrhoea. Unpaired't' test was done comparing the experimental and control group at different time series was higher than the table value $(\mathrm{t} 38=1.69)$ at $\mathrm{p}<0.05$ level of significant, hence research hypothesis was accepted i.e. acupressure was effective in reducing dysmenorrhoea.

\section{INTRODUCTION:-}

Dysmenorrhoea is derived from three words i.e 'dys' 'men' and 'rhein'. 'Dys' mean difficulty/ painful/ abnormal. 'men' means month and 'rhein' means to flow. 1 It is estimated that between sixty to seventy percent of women endure some degree of pain during period and cramping. Of those, approximately 10 percent experience contraction so extreme that they are one and a half times more powerful than labour pains. Every month many women suffer from pain around the time of their periods. For some women the pain can be so debilitating that they are forced to take time off or work or can only get through their periods by dosing themselves with pain killer.2 A national survey conducted among adolescent girls showed that $40 \%$ of the students frequently missed their school and college because of severe menstrual cramps. Dysmenorrhoea is responsible for significant absenteeism from work and it is the most common reason for school absence among adolescent's girls. 3 It has been reported that dysmenorrhoea can be successfully relieved by acupressure at Qihai (CV6), Guanyuan (CV4), Taichong (LIV3), Xuehai(SP10), Sanyinjiao (SP6). The sanyinjio acupoint is commonly used to induce labour and relieve pain during dysmenorrhoea. Dysmenorrhoea is a common problem among girls and acupressure is an effective non-invasive procedure to relieve pain. Acupoint Sanyinjiao (SP6) was selected for the study because it is the acupoint of choice in gynaecology and easy for girls to locate and apply pressure to without medical assistance. ${ }^{4}$

\section{The objectives of the study}

1. To determine the level of dysmenorrhoea before acupressure in control and experimental group by using a numerical pain rating scale.

2 . To determine the effectiveness of acupressure in reducing dysmenorrhoea in experimental group in terms of decrease in post-test pain score.

3. To find out the difference in post-test pain score of experimental and control group.

\section{Hypotheses}

$\mathrm{H}_{1}$ : There will be significant difference between the mean pretest and post-test score of dysmenorrhoea among student who are receiving acupressure.

$\mathrm{H}_{2}$ : There will be significant difference between the mean post-test pain score of experimental and control group.

\section{MATERIAL AND METHODS}

A quasi experimental non-equivalent control group time series design will be adopted for the study. The study was conducted in a college which offers graduate, post graduate and diploma course in nursing. The total number of students pursuing their studies were 495. Forty nursing students from First year and second year B.Sc nursing, who had moderate to severe dysmenorrhoea was selected using purposive sampling technique. The tool used were Baseline proforma and Numeric pain rating scale. The data collection period extended from 2nd April to 2nd June. After obtaining written permission from the authorities before data collection. Forty adolescent girls, 20 in Experimental group and 20 in Control group were selected by using purposive sampling method. Pre-test was conducted with the help of numerical pain rating scale in Experimental and Control group. The intervention was given by applying a thumb pressure over the Sp 6 point on left leg for 5 minute and change to right leg for another 5 minutes then continued alternatively for each leg completing a total period of 20 minutes. For each pressure cycle, on each side pressure was applied for six seconds and released for two seconds. Post test was conducted soon after, after 30 minutes and after 1 hour of intervention for Experimental group and without intervention for Control group.

\section{Results}

Description of baseline variables:-

Majority of the subjects of study ( $90 \%)$ belonged to the age group of 17-20. Fifty five percentages of experimental group and $60 \%$ of control group had menarche at the age 12-14 years. Majority of the subject in experimental group (70\%) 
and $55 \%$ of control group had the menstrual cycle for $25-30$ days. In experimental group $60 \%$ of subject had regular menstrual cycle whereas in control group all the subject had regular menstrual cycle. The entire subject in the experimental group as well as in the control group did not use any alternative method or medication of treatment for dysmenorrhoea. Maximum subject in the experimental group (80\%) as well as in the control group (65\%) used to experience associated symptom along with dysmenorrhoea during menstruation, Maximum subject of experimental group (70\%) and control group (67\%) had pain during the first day of menstruation.

Section I. Assessment of dysmenorrhoea at different time interval such as soon after, after $30 \mathrm{~min}$ and after 1 hour of intervention in experimental group and without intervention in control group.

Majority of the subjects $(60 \%)$ in the experimental group had severe pain $(60 \%)$ in pre-test, moderate pain (45\%) soon after intervention, mild pain after 30 minutes and 1 hour. Where as in control group majority of the subject had moderate pain in all the observation.

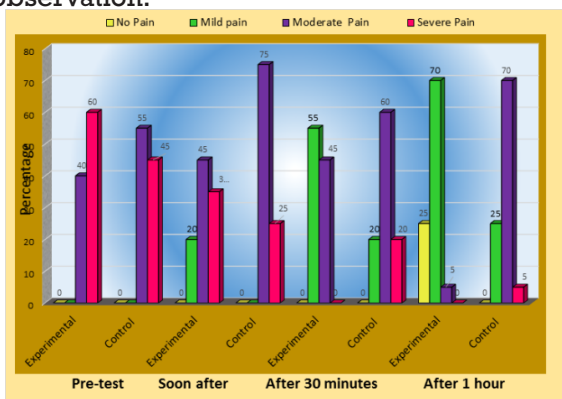

Figure 1: Multiple bar diagram showing the pain score

Section II. Effectiveness of acupressure on dysmenorrhoea within the various time interval of observation in the experimental group.

The analysis and interpretation of data (numeric pain score) on effectiveness of acupressure on dysmenorrhoea at different time interval of observation in the experimental group is shown in table 1 .

Table 1: F-value of experimental group base on numeric pain rating score at different time period.

$\mathrm{n}=20$

\begin{tabular}{|c|c|c|c|c|}
\hline Observation & Mean & SD & $\begin{array}{c}\text { Repeated } \\
\text { measure ANOVA } \\
\text { 'F' value }\end{array}$ & d.f \\
\hline Pretest & 7.95 & 1.468 & \multirow{2}{*}{344.881} & 3 and \\
Post-test 1 & 6.35 & 1.725 & & 57 \\
\hline Post-test 2 & 4.25 & 1.517 & & \\
\hline Post-test 3 & 1.25 & 1.164 & & \\
\hline
\end{tabular}

$t_{(\text {(and57) }}=2.765, p<0.05$

The data presented in the table 1 shows that there is significant difference between the pain score of post test $(F(3$ and 57) $=344.881$ ) at different time intervals. As the time interval increased there was remarkable improvement in the experimental group and there was reduction of pain among the subject. The statistical significance was very high in the experimental group $(p<0.05)$. So the null hypothesis is rejected and the research hypothesis is accepted.

Section Iii: Comparison Of Dysmenorrhoea Among Experimental And Control Group At Different Time Interval Of Observation.

The analysis and interpretation of data (numeric pain score) on effectiveness of acupressure on dysmenorrhoea at different time interval of observation in the experimental group in comparison with the control group is shown in table 2.

Table 2: Unpaired't' Test To Find The Difference In Mean Score Of Experimental Group And Control Group.

\begin{tabular}{|c|c|c|c|c|c|}
\hline \multicolumn{4}{|c|}{$t_{38}=1.69 p<0.05$} & \multicolumn{2}{|c|}{$n=20+20=40$} \\
\hline Observation & Group & $\begin{array}{c}\text { Mean } \\
\text { difference }\end{array}$ & $\begin{array}{c}\text { SD of } \\
\text { Differe } \\
\text { nce }\end{array}$ & $\begin{array}{c}\text { Change } \\
(\%)\end{array}$ & $\begin{array}{c}\text { 't' } \\
\text { value }\end{array}$ \\
\hline $\begin{array}{r}\text { Pre t } \\
\text { post t }\end{array}$ & \begin{tabular}{|c|} 
Experime \\
ntal \\
Control
\end{tabular} & .850 & $\begin{array}{l}.821 \\
.489\end{array}$ & $\begin{array}{l}20.13 \\
11.49\end{array}$ & .510 \\
\hline $\begin{array}{c}\text { Pretest- Post } \\
\text { test } 2\end{array}$ & \begin{tabular}{|c|} 
Experime \\
ntal \\
Control \\
\end{tabular} & & & $\begin{array}{l}46.54 \\
17.57\end{array}$ & 4 \\
\hline $\begin{array}{c}\text { Pre test - pos } \\
\text { test } 3\end{array}$ & \begin{tabular}{|c|} 
Experime \\
ntal \\
Control
\end{tabular} & 1.7 & $\begin{array}{l}1.174 \\
.865\end{array}$ & $\begin{array}{l}84.28 \\
22.97\end{array}$ & $\begin{array}{c}15.33 \\
5\end{array}$ \\
\hline $\begin{array}{l}\text { post test 1- } \\
\text { post test } 2\end{array}$ & \begin{tabular}{|c|} 
Experime \\
ntal \\
Control \\
\end{tabular} & $\begin{array}{c}2.100 \\
.450\end{array}$ & $\begin{array}{l}.553 \\
.510\end{array}$ & $\begin{array}{c}33.07 \\
6.87\end{array}$ & .81 \\
\hline $\begin{array}{l}\text { Post test 1- } \\
\text { post test } 3\end{array}$ & \begin{tabular}{|c|} 
Experime \\
ntal \\
Control \\
\end{tabular} & $\begin{array}{c}5.100 \\
.850\end{array}$ & $\begin{array}{l}1.294 \\
.813\end{array}$ & $\begin{array}{l}80.31 \\
12.98\end{array}$ & $\begin{array}{c}12.44 \\
0\end{array}$ \\
\hline $\begin{array}{l}\text { Post test 2- } \\
\text { post test } 3\end{array}$ & $\begin{array}{c}\text { Experime } \\
\text { ntal } \\
\text { Control }\end{array}$ & $\begin{array}{l}3.000 \\
.400\end{array}$ & $\begin{array}{l}.973 \\
.503\end{array}$ & $\begin{array}{c}70.59 \\
6.56\end{array}$ & $\begin{array}{c}10.61 \\
4\end{array}$ \\
\hline
\end{tabular}

The data presented in the table 2 shows that there is significant difference between all the observation, since calculated value of ' $t$ ' at various time intervals are very much higher than the table value $\mathrm{t} 38=1.69, \mathrm{P}<0.05$ level. Thus null hypothesis is rejected and research hypothesis is accepted.

\section{DISCUSSION}

The finding of the present study is consistent with the findings of other studies conducted in Iran to evaluate effect of acupressure on primary dysmenorrhoea in Iranian medical science students. The result showed significant difference in the scores of dysmenorrhoea between the two groups immediately after $(3.50 \pm 1.42 \mathrm{v} / \mathrm{s} 5.06 \pm 1.4, \mathrm{p}=0.004)$ and also 3 hours after treatment $(1.60 \pm 1.98 \mathrm{v} / \mathrm{s} 4.80 \pm 1.37, \mathrm{p}=0.000)$.

The finding of the study shows that in the experimental group the initial mean pain(pre-test) was higher than the mean pain score of post test (after the intervention) with further reduction on the mean pain score at various time interval. ANOVA for repeated measure was used to find out the significant difference in the pain between the various time periods. The results showed that there is significant difference in the pain score at different time interval in experimental group $(\mathrm{F}=344.881, \mathrm{P}<0.05$ level) who are receiving the acupressure.

The finding of the present study is consistent with the finding of other study conducted to evaluate the efficacy of Sanyinjiao (SP6) acupressure as a non- pharmacologic nursing intervention for dysmenorrhoea. The experimental group received acupressure treatment within the 8 hour of menstruation, severity of dysmenorrhoea were assessed prior to $30 \mathrm{~min}, 1,2,3$ hours following treatment. There was a significant difference in severity of dysmenorrhoea between the two groups immediately after $(F=18.50, p=0.000)$ and for up to 2 hours $(F=8.04, p=0.032)$ post treatment.

The finding of the present study is supported by the study conducted to find the effectiveness of acupressure on dysmenorrhoea. The result shows that Eighty-seven percent of the experimental group reported that acupressure was helpful and ninety-four percent were satisfied with acupressure in term of pain relief. ${ }^{7}$

Unpaired't' test was used to find out the effectiveness of 
acupressure on dysmenorrhoea on experimental group in comparison with the control group who did not received an acupressure treatment The result of the present study revealed that the mean difference between the pre-test and post-test 1 was $1.600 \pm .821$ in experimental group whereas the mean difference in control group was $.850 \pm .489$ which is lesser then the experimental group. The unpaired't' test showed that there is significant difference $(\mathrm{t}(38)=3.510 \mathrm{p}<$ 0.05 ) in the level of pain.

The finding of the study is supported by the experimental study conducted to find the effectiveness of acupressure in dysmenorrhoea where there was significant difference in the mean scores of the two groups of pre test and post test. It was observed that in experimental group there was huge reduction in mean pain score. ${ }^{8}$

\section{REFERENCES}

1. Venes D, Thomas. Cyclopedia Medical Dictionary. 19th ed. New Delhi: Jaypee Brothers Publishers; 2001.

2. Proctor M, Diagnosis and management of dysmenorrhoea. BMJ 2006; 232: 1134-1138.

3. Jen P, Chen P, Chiu T. Risk factors on the menstrual cycle of healthy gynae. 2009;49(1):689-93.

4. Chen HN, Chen $\mathrm{CH}$. Efeeect of acupressure at the sanjinjiao point on primary dysmenorrhoea. Journal of Advance Nursing: 2004 march:48(4), 380-387.

5. Mirbaqher-A, Jorpaz N, Adib-Hajbahery M, Mosaebi F. The effects of acupressure on primary dysmenorrhoea. [Available From: URL:http://www. ncbi.nlm.nih.gov/pubmed/21168112.]

6. Jun EM, Chang S, Kanq DH, Kim S. Effects of acupressure on dysmenorrhoea and skin temperature changes in college students. [online] Available from: URL:http://www.ncbi.nlm.nih.gov/pubmed/16782102.

7. Phawas D. Effect of acupressure on dysmenorrhoea among nursing students. The Nursing Journal of India.2016 July-Aug; 4:188-90.

8. Premalatha A "a study to assess the effectiveness of acupressure on dysmenorrhoea among adolescent girls (12-16 years) studying in sakthi higher secondary school.2010.3003216 